\title{
LA CRIMINALIZACIÓN DE LA INMIGRANTE EN EL DECRETO 70/2017: UN APORTE DESDE EL ANÁLISIS DEL DISCURSO ${ }^{1}$
}

\author{
THE CRIMINALIZATION OF THE IMMIGRANT IN THE ACT \\ 70/2017: A CONTRIBUTION FROM THE DISCOURSE ANALYSIS
}

\section{ROCÍO FLAX}

Instituto de Lingüística, Facultad de Filosofía y Letras, Universidad de Buenos Aires CONICET

rocioflax@educ.ar

\section{RESUMEN}

En el año 2003 se sancionó en Argentina la Ley de Migraciones 25871, que vino a reemplazar la legislación vigente desde la última dictadura cívico-militar. Esta ley reconoció la migración como un derecho humano y estableció su garantía por parte del Estado. En el año 2017, el Presidente Mauricio Macri firmó el Decreto de Necesidad y Urgencia 70/2017 que modificaba la Ley de Migraciones. En este trabajo buscamos determinar qué representaciones sociales se construyen sobre las migrantes en el DNU del año 2017 y a través de qué recursos se las legitima. Para ello analizaremos la introducción del decreto, correspondiente a los considerandos, donde se justifica la necesidad y la urgencia de cambios en la legislación del año 2003. Nuestra hipótesis de trabajo es que el decreto asocia de manera insistente a las migrantes con la criminalidad y con los problemas de inseguridad que tiene Argentina y, a su vez, legitima esta representación presentándola como una verdad evidente, conocida y aceptada por todas. De esta manera, se justifica la sanción de un DNU que restringe los derechos de las extranjeras que residen en el país. Para el análisis de las representaciones construidas en el DNU consideraremos: 1) la distribución de procesos y participantes en las cláusulas (Hodge y Kress, 1993) y 2) los marcos conceptuales que se activan (Lakoff, 2002, 2010) para hablar de las migrantes. Para el estudio de las formas de legitimación, seguiremos las categorías propuestas por Hart $(2010,2014)$.

Palabras clave: Discurso político, inmigración, representaciones sociales, marcos conceptuales, legitimación.

${ }^{1}$ El presente trabajo forma parte de la investigación posdoctoral Construcciones de la identidad y la alteridad a partir del signo "inmigrante" en el discurso político y legislativo argentino financiada por el Consejo Nacional de Investigaciones Científicas y Técnicas de Argentina (CONICET). 


\section{ABSTRACT}

In the year 2003 Migration Law No. 25871 was passed in Argentina. This law replaced the legislation in force since the last civic-military dictatorship and recognized migration as a human right, establishing guaranties by the Government. In 2017, President Mauricio Macri issued Act No. 70/2017 as a modificatory of the Migration Law. In this work, we seek to determine what social representations are constructed about immigrants in the Act of 2017 and what resources are used to legitimize them. We will analyze the introduction of the Act, the general considerations, which justify the need and urgency of changes in the legislation of 2003. Our working hypothesis is that the Act insistently associates immigrants with criminality and the insecurity feeling present in Argentina at that moment, and in turn, legitimizes this representation by presenting it as an evident truth, known and accepted by all. Therefore, the Act restricts the rights of foreigners residing in the country and shows this restriction as justified. For the analysis of the representations we will consider: 1) the distribution of processes and participants in the clauses (Hodge and Kress, 1993) and 2) the conceptual frames that are activated (Lakoff, 2002, 2010) to talk about the immigrants. For the study of forms of legitimation, we will follow the categories proposed by Hart $(2010,2014)$.

Keywords: Political discourse, immigration, social representations, frames, legitimation.

Recibido: 24/03/2019. Aceptado: 15/06/2019.

\section{INTRODUCCIÓN}

Zn el año 2003 se sancionó la Ley de Migraciones 25.871, que vino a reemEplazar la legislación vigente desde la última dictadura cívico-militar. Esta ley reconoció la migración como un derecho humano y estableció, por lo tanto, su garantía por parte del Estado. Asimismo, aseguró para todas las migrantes -sin importar si permanecían en una condición de irregularidad- los derechos civiles y sociales (educación, salud, igualdad de derechos para los servicios sociales y derecho a un proceso en situación de detención) (Giustiniani, 2004). En el año 2017, el Presidente Mauricio Macri firmó el Decreto de Necesidad y Urgencia 70/2017 que modificó la Ley de Migraciones.

En este trabajo buscamos determinar qué representaciones sociales se construyen sobre las personas que inmigran al país en el DNU del año 2017. Para ello, analizaremos la introducción del decreto, correspondiente a los considerandos, donde se justifica la necesidad y la urgencia de cambios en la legislación migratoria. Nuestra hipótesis de trabajo es que el decreto no solo asocia de manera insistente a las migrantes con la criminalidad y con los problemas de seguridad que tiene el país, sino que utiliza una serie de estrategias discursivas para postular 
dicha representación como una verdad evidente, un conocimiento compartido y aceptado por la mayoría.

Para el análisis de las representaciones construidas en el DNU consideraremos: 1) la distribución de procesos y participantes en las cláusulas (Hodge y Kress, 1993) y 2) los marcos conceptuales que se activan (Lakoff, 2002, 2010) para hablar de las personas migrantes. Por su parte, para el estudio de las formas de legitimación de dichas representaciones, seguiremos las categorías propuestas por Hart (2010, 2014), quien considera que los dos recursos básicos para legitimar representaciones son la evidencialidad y la modalidad epistémica.

\section{BREVE REPASO HISTÓRICO}

La Ley Videla, sancionada en 1981, tuvo como uno de sus objetivos el fomento de la inmigración como método para aumentar la población. A diferencia de la Ley Avellaneda del siglo XIX, no se trataba de poblar el territorio, sino de solucionar la escasez de mano de obra. De cualquier forma, prevalecía un objetivo utilitarista y no una política receptiva por considerar la migración como un derecho. Además, esta ley era restrictiva con respecto al tipo de inmigrantes que se recibiría. El artículo segundo indicaba que "promoverá la inmigración de extranjeros cuyas características culturales permitan su adecuada integración en la sociedad argentina", mientras que el tercero otorgaba al Poder Ejecutivo la potestad de determinar en qué zonas del país se establecerían.

Sin un apartado referido a derechos y obligaciones de las migrantes, dejaba en claro las condiciones para su ingreso y expulsión:

Respecto de los inmigrantes limítrofes se formulan políticas restrictivas, ampliándose las actividades de control y expulsión². Subyace en la Ley General de Migraciones la 'Doctrina de seguridad nacional'; se observa el fenómeno migratorio desde una óptica casi exclusivamente policial incompatible con las garantías otorgadas por los instrumentos del 'derecho internacional de los Derechos Humanos' (Oteiza y Novick, 2010: p. 7).

La Ley Videla se mantuvo aún en democracia hasta el año 2003. La Ley de Migraciones sancionada a fines de dicho año, durante la presidencia de Néstor Kirchner, tiene, por el contrario, un carácter netamente receptivo. Reconoce la migración como un derecho esencial e inalienable de toda persona, garantizado

${ }^{2}$ Cabe destacar que las expulsiones podían realizarse sin que medie ningún tipo de proceso judicial, por la simple disposición de las autoridades migratorias. 
por el Estado. El objetivo final de la nueva norma es la libre circulación de personas por la región, por ello contempla un marco de integración y otorga a los países de la región un trato diferenciado. Por ejemplo, considera como ciudadanas residentes temporarias a las nativas del Mercosur, de Chile y de Bolivia.

La actual ley permite la entrada al país de cualquier persona que así lo desee e implementa una serie de mecanismos para subsanar las situaciones de irregularidad en las que pudieran estar incurriendo las migrantes. Si bien aparece el concepto de "ilegalidad de permanencia", el hincapié se encuentra puesto en la irregularidad y no se prevé para estos casos la expulsión, sino la ayuda para la regularización. El decreto sancionado por el Presidente Mauricio Macri en el año 2017 elimina, entre otras cosas, esta posibilidad: la persona que haya ingresado al país de manera irregular debe abandonar el territorio y, luego, se contemplará la posibilidad de su ingreso regular.

\section{METODOLOGÍA}

Partiendo de una postura funcionalista, a continuación detallamos los tres ejes de análisis que emplearemos para observar qué tipo de representaciones se construyen sobre las migrantes en los considerandos del DNU 70/2017 y cómo se legitiman dichas representaciones.

Según Hart (2010, 2014), el discurso político -entendido en un sentido amplio, que incluye el discurso de los medios de comunicación, el discurso legislativo, etc. - tiene como objetivo la coerción, en el sentido de generar un cambio en las representaciones de las personas y, por lo tanto, en sus actitudes y comportamientos. Para ello, se vale de dos estrategias, la representación y la legitimación.

Para el análisis de las representaciones, en primer lugar, analizamos la distribución de procesos y participantes a partir de la propuesta de la Lingüística Crítica (Fowler, Kress, Hodge y Trew, 1983; Hodge y Kress, 1993). El concepto de "proceso" -tomado de la Lingüística Sistémico-Funcional (Halliday y Matthiessen, 2014) - refiere a aquello que posee una dimensión temporal. De esta forma, lo procesos incluyen a los verbos, conjugados o en sus formas no finitas (gerundio, participio, infinitivo), pero también a las nominalizaciones.

Las participantes pueden ser relacionadas de distintas formas con los procesos: pueden ser actoras de los procesos, afectadas, circunstancias o pueden estar conectadas con otros objetos (entidades relacionantes). La cláusula típica, denominada "transactiva", está formada por dos participantes vinculadas entre sí por un proceso. Estas cláusulas se caracterizan por el hecho de que una de sus participantes posee el rol de actora y la otra, de afectada. Las cláusulas no transactivas son aquellas que poseen una sola participante -actora o afectada- asociada a un proceso. Las cláusulas transactivas y las no transactivas componen lo que se denomina el 
"modelo accional" de representación. En cambio, el modelo relacional supone un tercer tipo de cláusula que establece una relación entre una entidad relacionante y otro elemento: las relacionales ecuativas sirven para establecer una identificación entre ambas participantes; las relacionales atributivas le adscriben características a la entidad relacionante; y las posesivas indican una relación de posesión (que en algunos casos puede esconder relaciones de entidad-atributo o pertenencia). En este trabajo nos concentraremos en las cláusulas accionales.

Los procesos transactivos muestran una diferencia entre participantes que poseen agentividad y aquellas que no. La posibilidad de actuar sobre otras entidades o sobre otras personas es una indicación de poder. Además, la causalidad en las cláusulas transactivas es explícita. Sin embargo, no es este el caso de las cláusulas no transactivas. Los modelos no transactivos pueden generar cierta confusión en tanto en algunos casos no queda claro si la entidad involucrada es actora o afectada.

En segundo lugar, la teoría del Framing propuesta por Lakoff $(2002,2010)$ nos permite analizar con qué categorías o áreas de la experiencia se asocia a las diferentes participantes que aparecen en un discurso. La idea básica de esta teoría es que las personas humanas almacenamos el conocimiento en forma de marcos o fragmentos de experiencia. Los marcos son estructuras abiertas de conocimiento enciclopédico, imágenes esquemáticas y metáforas que representan la experiencia que poseemos sobre cada dominio cultural. Son idealizados en el sentido de que constituyen una decantación de experiencias repetidas (sean experiencias de primera mano o mediadas por el lenguaje u otros modos semióticos) (Hart, 2010). Los marcos, que se encuentran en la memoria de largo plazo, se activan cuando aparecen determinados elementos léxicos en un discurso que estamos procesando. Al mismo tiempo, constituyen el fondo a partir del cual comprendemos dichos discursos, los analizamos y realizamos asociaciones. Para conceptualizar una situación, un evento, un objeto o una entidad, las hablantes podemos activar diferentes marcos de diversas maneras. Por ello, qué marcos son activados para conceptualizar a un grupo de personas -en este caso las personas que migran- permite echar luz sobre la ideología subyacente a un discurso y, por lo tanto, sobre las asociaciones que ese discurso quiere activar en quien lo lea.

Además, la importancia de analizar los marcos conceptuales reside en que cada vez que un marco se utiliza para hablar de un tema en particular (por ejemplo, en nuestro caso, sobre las migrantes), la asociación entre ese tema y ese marco se fortalece en la mente de las hablantes y las oyentes. Esto se debe a que el procesamiento de los marcos utilizados en un discurso se realiza de manera automática, por lo tanto, no es algo que podamos evitar. De esta manera, es muy difícil ser conscientes de los marcos que usamos o escuchamos para poder criticarlos, en lugar de tomarlos como lo dado por sentado.

Para el análisis de las formas de legitimación, seguimos la clasificación pro- 
puesta por Hart (2010), quien considera que existen dos recursos básicos para legitimar las representaciones que aparecen en un discurso: la evidencialidad y la modalidad epistémica. La evidencialidad es el término que refiere a las diferentes formas que tenemos las hablantes para calificar un enunciado según las fuentes de información. Es particularmente importante en el discurso estratégico porque las oyentes de un texto pueden reconocer la evidencia, incluso si no tienen ninguna confianza en la hablante. Por su parte, la modalidad epistémica es el término que se utiliza para los dispositivos que permiten expresar los grados de compromiso o creencia que tienen las hablantes con respecto a las representaciones que aparecen en el discurso.

Para el análisis de los tipos de evidencialidad utilizamos la siguiente clasificación adaptada de Hart (2010) y de Bednarek (2006):

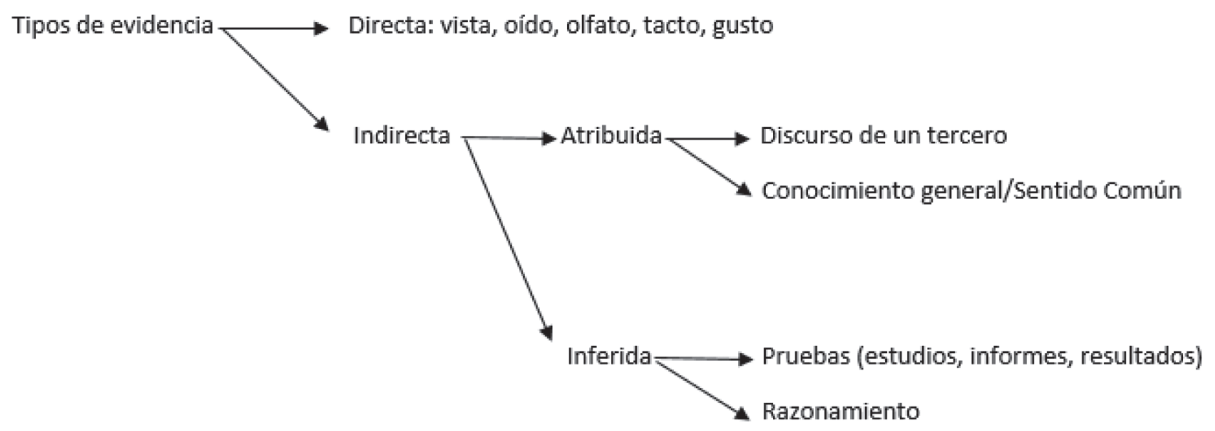

Figura 1. Tipo de evidencialidad.

Por su parte, la modalidad epistémica refiere al grado de conocimiento expresado por la hablante en términos de certeza, probabilidad, posibilidad e improbabilidad. Según Hart (2010), a su vez, el grado de certeza con que una hablante evalúa sus dichos da cuenta de su autoridad, categoría gradual que varía desde la máxima autoridad para las certezas hasta la mínima autoridad para lo improbable. Es necesario tener en cuenta que, en el lenguaje, marcar la modalidad epistémica es obligatorio. Según Fowler (1991:85), 'a speaker/writer must always indicate a commitment to the truth (or otherwise) of any proposition s/he utters, or to a prediction of the degree of likelihood of an event described taking place. ${ }^{3}$ " Por

3 "Una hablante/escritora siempre debe indicar su compromiso con la verdad (o al contrario) de cualquier proposición que formule, o con una predicción del grado de probabilidad de que un evento descrito tenga lugar" (traducción nuestra). 
lo tanto, la falta de un verbo modal epistémico no indica que la hablante no está expresando ningún tipo de modalidad epistémica: la certeza absoluta en castellano tiene una marca-cero.

\section{ANÁLISIS}

\subsection{Estrategias referenciales}

En este apartado analizamos la manera en que se denomina a la participante que refiere a las personas que no nacieron en Argentina, según la clasificación propuesta en Hart (2010). El resultado del análisis se puede observar en la Tabla I:

Tabla I. Estrategias referenciales.

\begin{tabular}{|l|l|}
\hline Nacionalismos & $\begin{array}{l}\text { Los no nacionales - Personas de nacionalidad extranjera (3 } \\
\text { ocurrencias) - La población de personas de nacionalidad ex- } \\
\text { tranjera }\end{array}$ \\
\hline Antropónimos & $\begin{array}{l}\text { Los extranjeros - (población) extranjera - Las personas extran- } \\
\text { jeras - Los extranjeros con antecedentes delictivos - Personas } \\
\text { de nacionalidad extranjera (3 ocurrencias) - La población de } \\
\text { personas de nacionalidad extranjera - La población extranjera } \\
\text { (2 ocurrencias) - Un extranjero - Aquellos extranjeros - La } \\
\text { persona extranjera }\end{array}$ \\
\hline Accionismos & $\begin{array}{l}\text { El migrante (2 ocurrencias) - Quienes hubieren ingresado en } \\
\text { forma clandestina al territorio nacional - Los migrantes (dos } \\
\text { ocurrencias) }\end{array}$ \\
\hline
\end{tabular}

Si bien es bastante probable y no constituye una sorpresa que, en un decreto sobre migraciones se hable sobre "inmigrantes" o "extranjeros" -aunque siempre podrían ser referidas de otras maneras, por ejemplo, "personas que ingresan al país" o, simplemente, "personas"-, vale la pena destacar que la presencia de este tipo de expresiones son la precondición para la división de la sociedad entre un in-group y un out-group. Además, no es lo mismo hablar de "migrantes" -denominación seleccionada por la comunidad migrante en Argentina ${ }^{4}$ - que de "extranjeras" -cuya etimología remite a la palabra "extraño"- o exaltar la idea de nación. Por último, cabe destacar que dos de estas referencias incluyen valoraciones más explícitas, que asocian a las extranjeras con el crimen ("los extranjeros con antecedentes delicti-

\footnotetext{
${ }^{4}$ Cfr. con https://www.facebook.com/migrarnoesdelito/
} 
vos", "quienes hubieran ingresado en forma clandestina al territorio nacional").

La única participante -si bien en muchos casos se encuentra elidida, ya que es propio de este género discursivo la eliminación de participantes a partir del uso de verbos en infinitivo y nominalizaciones- que interactúa con las personas migrantes es el Estado Nacional: "Estado Nacional", "autoridad migratoria", "la justicia". A continuación analizamos los procesos asociados a las migrantes.

\subsection{Estrategias de predicación}

En este apartado observamos las acciones con las que son vinculadas las migrantes, ya sea como actoras o como afectadas. Incluimos también las nominalizaciones cuyas participantes pueden ser repuestos tanto por la sintaxis como por el significado global del texto. Luego de realizar un relevo de cada uno de los procesos que tenían como participante a las migrantes, obtuvimos los siguientes resultados, volcados en las tablas II y III:

Tabla II. Distribución de procesos (verbos) y participantes en relación con las migrantes.

\begin{tabular}{|l|l|}
\hline Actora & Afectada \\
\hline 13 & 11 \\
\hline Pueden ejercer & Gozan de (todos los derechos civiles del \\
(Pueden) comprar & ciudadano) \\
(Pueden) enajenar & Respetando (derechos) \\
(Pueden) navegar & Suscita (incertidumbre) \\
(Pueden) ejercer & Detenida \\
(Pueden) testar & Asiste \\
(Pueden) casarse & No asiste \\
Permanecer & Garantizado \\
Hubieran ingresado & Se prevé (un supuesta de dispensa) \\
Eludiendo (el control migratorio) & Se incorpora (la figura del advenimiento) \\
Preste auxilio (a la justicia) & Facilitando (reingreso) \\
Acceder a (nacionalización) & Resguardando (derechos) \\
Defrauda (ley migratoria) & \\
\hline
\end{tabular}


Tabla III. Nominalizaciones que presuponen a la migrante como actora o afectada.

\begin{tabular}{|l|l|}
\hline Actora & Afectada \\
\hline 28 & 22 \\
\hline Movilidad & Admisión \\
Entrada & Expulsión \\
Salida & Respeto \\
Permanencia & Protección \\
Permanencia & Expulsión \\
Participación & Expulsiones \\
Infracción & Controles \\
Uso (abusivo y contrario) & Expulsión \\
Hechos delictivos & Respeto \\
Delitos & Control \\
Avenimiento & Integración \\
Reingreso & Dispensa \\
Fraude & Reunificación (de la familia) \\
Residencia & Expulsión \\
Arraigo & Expulsión \\
Naturalización & Retención \\
Delitos & Anoticiamiento \\
Tráfico (armas) & Retención \\
Lavado (dinero) & Notificación \\
Inversiones (actividades ilícitas) & Asistencia \\
Trata (de personas) & Controles \\
Acto (de terrorismo) & (Sin) Menoscabo \\
Delito & \\
Acto (Susceptible de ser juzgado...) & \\
Fraude & \\
Fraude & \\
Delito & \\
Violencia & \\
& \\
\hline
\end{tabular}

A partir de las tablas II y III, observamos que las acciones vinculadas con las migrantes se enmarcan dentro de tres marcos conceptuales: los derechos (su goce o restricción), el crimen y la inseguridad 5 . En tanto los marcos constituyen redes de

\footnotetext{
${ }^{5} \mathrm{Si}$ bien estas conclusiones se ajustan tanto a las formas verbales como a las nominalizaciones, observamos que en las formas verbales -en las cuales las migrantes son asociadas con los procesos de manera explícita a través de la sintaxis del texto- predominan las acciones que estas realizan conforme al derecho y las acciones que el Estado argentino dispone para garantizar sus derechos; mientras que en las nominalizaciones -más abundantes y más difíciles de refutar (Amossy y Herschberg Pie-
} 
significados, algunos de ellos incluyen referencias a otros marcos. Esto se encuentra indicado, a continuación, a través de los paréntesis. Así el marco conceptual de los derechos contiene referencias a la familia, el trabajo, etc.; y el marco conceptual del delito incluye la asociación entre crímenes que no necesariamente son violentos (por ejemplo, el fraude) y diferentes formas de violencia:

1) Derechos (Trabajo, Economía, Religión, Familia, Desplazamiento): "los extranjeros gozan en el territorio de la Nación de todos los derechos civiles del ciudadano y pueden ejercer su industria, comercio y profesión, poseer bienes raíces, comprarlos y enajenarlos, navegar los ríos y costas, ejercer libremente su culto, testar y casarse conforme a las leyes"; "respetando los principios de Derechos Humanos y la movilidad de los migrantes"; "versa sobre la entrada, salida o permanencia de población nacional o extranjera dentro de su territorio".

2) Delincuencia (Violencia): "la permanencia de los extranjeros con antecedentes delictivos", "en relación a los delitos vinculados a la narcocriminalidad, se observa que el TREINTA Y TRES POR CIENTO (33\%) de las personas bajo custodia del SERVICIO PENITENCIARIO FEDERAL son extranjeros"; "aquellos casos en los que personas de nacionalidad extranjera se encontraran involucradas en hechos delictivos"; "delitos que merecen, según las leyes argentinas, penas privativas de la libertad y en particular los delitos de tráfico de armas, de personas, de órganos o tejidos y de estupefacientes, lavado de dinero, inversiones en actividades ilícitas, trata de personas, genocidio, crímenes de guerra, actos de terrorismo o delitos de lesa humanidad y de todo otro acto susceptible de ser juzgado por la Corte Penal Internacional"; "que ante la aparición de las nuevas modalidades de fraude a la ley migratoria precedentemente señaladas y la necesidad de llevar adelante nuevas estrategias contra el delito y la violencia".

3) Inseguridad: "se busca imprimir mayor celeridad al procedimiento de actuación administrativa en el orden migratorio y resguardando debidamente la seguridad pública y los derechos de los migrantes"; "que, en virtud de lo expuesto, el dictado del presente resulta consistente con las razones que, en su oportunidad, motivaron el Decreto No 228 de fecha 21 de enero de 2016 mediante el cual se declaró la emergencia de seguridad pública"; "deviene imprescindible ajustar la legislación migratoria a la nueva realidad, sin menoscabo de los derechos y garantías de los migrantes y preservando adecuadamente la seguridad pública", "que tanto ese bien común como el interés general de la sociedad se ven actualmente afectados por las graves consecuencias que provocan los delitos".

rrot, 2010)- predominan las acciones criminales y las medidas de control, retención, expulsión, etc., tomadas por el Estado argentino. 
Con respecto al marco conceptual del crimen, resulta interesante que el decreto separa los diferentes delitos considerados por la legislación argentina del delito de ingresar al país de manera irregular. Sin embargo, a pesar de nombrarlos por separado, los equipara al considerar que deben ser tratados de la misma manera: a través de un proceso expeditivo que determine la expulsión de la persona extranjera:

1) Que la situación reseñada precedentemente justifica la regulación inmediata de un procedimiento migratorio especial de carácter sumarísimo, aplicable a aquellos casos en los que personas de nacionalidad extranjera se encontraran involucradas en hechos delictivos y a quienes hubieren ingresado en forma clandestina al territorio nacional, eludiendo el control migratorio.

Esto podría parecer natural, en tanto entrar de manera ilegal a un lugar sería un delito. No obstante, consiste justamente en uno de los puntos centrales del endurecimiento de la política migratoria. En la ley del 2003, no solo no existían los procedimientos sumarísimos para determinar la expulsión de una persona, sino que en el caso de que hubiera ingresado al país de manera irregular, en primera instancia, se promovía su regularización ${ }^{6}$. Al modificar el concepto de irregularidad por el término "clandestina" se activa el marco de la criminalidad para conceptualizar a quienes ingresaron al país sin contar con los papeles y permisos para radicarse.

La criminalización de la migrante incluye otras dos estrategias para generar miedo en la población. Se habla de delitos conocidos o nuevas formas de delito, pero no se los describe. Es decir que queda para la imaginación de la lectora figurarse qué clase de delitos cometen las migrantes. Y, en otra instancia, se las asocia no con delitos menores, sino con la categoría de delitos considerada más grave (delitos de tráfico de armas, de personas, de órganos o tejidos y de estupefacientes, lavado de dinero, inversiones en actividades ilícitas, trata de personas, genocidio, crímenes de guerra, actos de terrorismo o delitos de lesa humanidad):

2) "Que provocan los delitos que merecen, según las leyes argentinas, penas privativas de la libertad y en particular los delitos de tráfico de armas, de personas, de órganos o tejidos y de estupefacientes, lavado de dinero, inversiones en actividades ilícitas, trata de personas, genocidio, crímenes de guerra, actos de terrorismo o delitos de lesa humanidad y de todo otro acto susceptible de ser juzgado por la Corte Penal Internacional".

\footnotetext{
${ }^{6}$ No solo hay que tener en cuenta que la ley del año 2003 estipula un plazo para la regularización de la situación migratoria antes de considerar la expulsión, sino que la reglamentación y cumplimiento de la ley incluyó al Programa Patria Grande, que permitió regularizar la situación de migrantes que se encontraran en alguna situación contraria a la ley. Todo esto en concordancia con la consideración de que el flujo de personas a través de los países constituye no solo algo normal, sino un derecho (Arias Duval, 2011).
} 
Hart $(2010,2014)$ considera que existe un recurso -la proximidad- que se utiliza para complementar las predicaciones que representan a las migrantes como un peligro y, así, elevar el nivel de amenaza que constituyen para las miembros del in-group. En este caso, observamos cómo el riesgo se presenta como inminente temporalmente ("urgente", "inmediata", "sumarísimo") y, además, se eleva la carga semántica de la gravedad que conlleva ("crítica”):

3) "Que lo hasta aquí expuesto configura una situación crítica que amerita la adopción de medidas urgentes".

4) "justifica la regulación inmediata de un procedimiento migratorio especial de carácter sumarísimo”.

\subsubsection{Interpretación de los datos}

Según diferentes autores (Hart, 2010; Wodak, 2001) hay una serie de topoi -presentados en la Tabla IV- propios del discurso xenófobo que se utiliza para persuadir de la amenaza que constituyen las migrantes:

Tabla IV. Topoi recurrentes y sus asociaciones típicas. Fuente: Hart (2010).

\begin{tabular}{|l|l|}
\hline Topos & Asociación/premise \\
\hline Carga & El out-group necesita ser mantenido por el in-group \\
\hline Carácter & El out-group tiene ciertas características indeseables \\
\hline Crimen & El out-group está compuesto por criminales \\
\hline Cultura & $\begin{array}{l}\text { El out-group tiene diferentes normas y valores que el in-group } \\
\text { and y son incapaces de asimilación }\end{array}$ \\
\hline Peligro & El out-group es peligroso \\
\hline Desventaja & $\begin{array}{l}\text { El out-group no trae ninguna ventaja o no es de ninguna uti- } \\
\text { lidad para el in-group }\end{array}$ \\
\hline Enfermedad & El out-group es sucio y transmite enfermedades contagiosas \\
\hline Desplazamiento & $\begin{array}{l}\text { El out-group va a eventualmente sobrepasar en número o va } \\
\text { a dominar al in-group y va a tener acceso privilegiado a los } \\
\text { recursos socio-económicos limitados por sobre el in-group }\end{array}$ \\
\hline Explotación & $\begin{array}{l}\text { El out-group explota el sistema de servicios sociales del in- } \\
\text { group }\end{array}$ \\
\hline Finanzas & El out-group presenta un costo económico para el in-group \\
\hline
\end{tabular}


A partir del análisis presentado, observamos que el decreto activa dos de los topoi recurrentes en el discurso xenófobo: los topoi del crimen y del peligro. La activación de representaciones de crimen e inseguridad activa una respuesta emocional básica: el miedo. Las emociones, a su vez, condicionan nuestras actitudes y acciones: lo lógico frente a una situación amenazante es hacer algo para evitar el peligro o para resguardarse. Cuando en un discurso se representa una situación como una amenaza inminente, lo que se busca es activar cierto tipo de respuestas en las lectoras. En este caso, el decreto brinda él mismo la solución al problema que construyó, una solución que parecería lógica: eliminar lo que es peligroso. En este sentido, el endurecimiento de las políticas migratorias se encuentra, por lo tanto, totalmente justificado por la activación reiterada de los topoi del crimen y el peligro.

The topoi of danger, displacement and disease, then, appeal to innate fears of physical harm, loss of territorial control and cultural identity, and infection from transmittable diseases. They are all based on the same conditional: 'if a political action or decision bears specific dangerous, threatening consequences, one should not perform it' (Wodak, 2001: 75). Or alternatively formulated: 'if there are specific dangers and threats, one should do something against them"7 (Hart, 2010: 83).

Del análisis de los procesos y caracterizaciones de las migrantes se infiere una tensión entre sus derechos y la seguridad pública. En el medio, queda la asociación de las personas que migran con diversos tipos de delitos, incluidos algunos que suponen formas de violencia. De esta manera, lo que podemos concluir es que el decreto justifica la restricción de los derechos de quienes provienen de otros países apelando a su función de garantizar la seguridad de las argentinas.

\subsection{Legitimación}

A continuación analizamos las estrategias que despliega el decreto para legitimar su representación de las migrantes como criminales y como una amenaza para la seguridad de las argentinas.

7 "Los topoi del peligro, el desplazamiento y la enfermedad, entonces, apelan a los temores innatos de daño físico, pérdida del control territorial e identidad cultural, e infección por enfermedades transmisibles. Todos se basan en el mismo condicional: 'si una acción o decisión política conlleva consecuencias peligrosas y amenazantes específicas, no se debe realizar' (Wodak, 2001: 75). $\mathrm{O}$ formulado alternativamente: 'si hay peligros y amenazas específicos, una debería hacer algo contra ellos"” (traducción nuestra). 


\subsubsection{Uso de evidenciales}

a) Pruebas y razonamiento

5) "Que, a su vez, la población de personas de nacionalidad extranjera bajo custodia del SERVICIO PENITENCIARIO FEDERAL se ha incrementado en los últimos años hasta alcanzar en 2016 el VEINTIUNO COMA TREINTA Y CINCO POR CIENTO (21,35\%) de la población carcelaria total.

Que por otro lado, en relación a los delitos vinculados a la narcocriminalidad, se observa que el TREINTA Y TRES POR CIENTO (33\%) de las personas bajo custodia del SERVICIO PENITENCIARIO FEDERAL son extranjeros. Ello denota que la población extranjera detenida en dependencias del SERVICIO PENITENCIARIO FEDERAL por infracción a la Ley No 23.737 está altamente representada entre los detenidos, teniendo en cuenta que, conforme el último censo nacional, la participación de la población extranjera como porcentaje de la población total es del CUATRO COMA CINCO POR CIENTO (4,5\%)"

Las pruebas utilizadas son estadísticas de la Procuración Penitenciaria de la Nación, aunque el decreto no menciona la fuente ${ }^{8}$. Constituyen lo que se considera "datos duros", es decir, fórmulas matemáticas que, desde el sentido común, no podrían ser manipulables y cuya interpretación sería univoca (Chalmers, 1982; Kuhn, 1990; Wittgenstein, 1978). De esta manera, se considera que son objetivos -no dependen de la subjetividad o interpretación de quien haya realizado el cálculo- y estarían representando la realidad tal cual es. A partir del uso de un verbo impersonal, "se observa", que no permite reponer a la actora, presenta las estadísticas como si se tratara de evidencia directa (proveniente del sentido de la vista) y no como un caso de discurso ajeno referido.

El dato, a su vez, habilita obtener información a partir de un razonamiento que, en tanto implica una estructura lógica deductiva, tampoco podría ser objetado: si las migrantes representan el 4,5\% de la población argentina (otro dato cuya fuente no se encuentra explicitada, pero corresponde al censo del año 2010 ) y el $21,35 \%$ de las personas bajo custodia es extranjera (no se aclara en qué condiciones, es decir, por ejemplo, si tienen condena firme o por qué clases de delito fueron encarceladas, tampoco si residían o no en el país), la conclusión es que las extranjeras están altamente representadas con respecto a la población carcelaria total. Otra forma de expresar la conclusión es que las migrantes tienden a cometer más delitos que las argentinas.

Los porcentajes son engañosos por dos razones. Los datos descontextualizados

${ }^{8} \mathrm{http} / /$ ppn.gov.ar/?q=informes-anuales

${ }^{9}$ https://www.indec.gov.ar/nivel4_default.asp?id_tema_1=28id_tema_2=418id_tema_3=135 
siempre pueden ser manipulados para los objetivos de quien los utiliza (Chalmers, 1982; Kuhn, 1990; Wittgenstein, 1978). En primer lugar, dijimos que presentar el porcentaje de migrantes bajo custodia activa la creencia de una mayor tendencia a la criminalidad por parte de las personas que nacieron en otros países. Sin embargo, lo que no se dice, pero también se desprende de la estadística, es que la mayoría de las delincuentes son argentinas. En segundo lugar, la presencia de datos como forma de argumentación no deja lugar para la consideración de otros factores. Por ejemplo, en la referencia al $22 \%$, ¿de qué tipo de delitos se trata?, ¿delitos violentos, asesinatos, violaciones?, ¿hurtos menores?, ¿delitos típicamente vinculados con situaciones de pobreza? ¿Existe alguna razón en la Argentina que explique por qué las migrantes delinquen en esa proporción? Por ejemplo, no dice nada sobre las oportunidades laborales para las personas que vienen de otros países.

Con respecto a los crímenes vinculados al narcotráfico, ¿cuál es el total de personas detenidas por el narcotráfico? No es lo mismo el 33\% de un total de 100 personas que, de 10.000 , aunque la relación entre migrantes y argentinas se mantenga idéntica. Estas narcocriminales ‘habitaban el suelo argentino, se radicaron especialmente para realizar el negocio ilícito o solo estaban de paso (lo que las excluiría de las personas que vienen al país para radicarse)? ¿Ese alto porcentaje incluye a personas que se encuentran solamente detenidas o ya condenadas?

b) Discurso de un tercero

6) "Que, al respecto, la CORTE INTERAMERICANA DE DERECHOS HUMANOS definió que la política migratoria de un Estado está constituida por todo acto, o medida institucional (leyes, decretos, resoluciones, directrices, actos administrativos, etc.) que versa sobre la entrada, salida o permanencia de población nacional o extranjera dentro de su territorio. Agregando, que dicha facultad es potestad del Estado Nacional, asintiendo con que éstos cuentan con un ámbito de discrecionalidad para fijar las políticas migratorias (OC-18/03; "Caso Vélez Loor vs. Panamá”, Sentencia de 23 de Noviembre de 2010, Excepciones Preliminares, Fondo, Reparaciones y Costas y "Caso de Personas Dominicanas y Haitianas Expulsadas vs. República Dominicana” Sentencia de 28 de Agosto de 2014, Excepciones Preliminares, Fondo, Reparaciones y Costas)”.

En este caso, el discurso referido constituye una cita de autoridad que avala el discurso y las decisiones del Poder Ejecutivo. Es decir, si la autoridad del Poder Ejecutivo no fuera suficiente, debería serlo la de una institución que se dedica a garantizar el cumplimiento de los derechos humanos en América.

El primer párrafo de la cita de la Corte Interamericana de Derechos Humanos constituye una definición de política migratoria bastante escolar que, en principio, 
no suma ningún tipo de información sobre las razones que motivan el decreto. Luego, la cita continúa y aparece el aval buscado. La palabra clave es "discrecionalidad”, que otorga respaldo para las modificaciones a la ley que vendrán a continuación. Como quien se adelanta a posibles objeciones frente a una acción reprochable, el decreto justifica mediante una cita de autoridad que el Estado puede plantear la política migratoria que desee sin aclarar, al menos en esta parte del texto, los límites de esa discrecionalidad.

Efectivamente esos límites no aparecen en la cita de autoridad, sino que se explican más adelante. Sin embargo, la alusión a la protección de los Derechos Humanos se reduce, básicamente, a ser expedita a la hora de expulsar a las migrantes:

7) Que también es evidente que el ejercicio de dicha potestad debe hacerse con pleno respeto de los derechos de las personas extranjeras y en forma compatible con las normas de protección de los Derechos Humanos.

Que el adecuado cumplimiento de dicho objetivo se ve seriamente dificultado por la actual duración de los procesos administrativos y judiciales en materia migratoria, los que atentan contra el debido proceso legal y pueden acarrear al Estado Nacional responsabilidad internacional, de conformidad con lo resuelto por la CORTE INTERAMERICANA DE DERECHOS HUMANOS en reiterados fallos. Que la aplicación de las normas vigentes conduce al desarrollo de procedimientos administrativos y actuaciones judiciales de muy prolongada extensión, los que conforme a los plazos legalmente previstos pueden insumir alrededor de CUATROCIENTOS (400) días hábiles. Esta circunstancia suscita incertidumbre al migrante respecto de su situación y dificulta a la DIRECCIÓN NACIONAL DE MIGRACIONES el cumplimiento de su misión de garantizar el cumplimiento de la ley, lo que en última instancia repercute en la seguridad pública.

El pleno derecho no se refiere, por ejemplo, al derecho humano a habitar en la parte del mundo que se desee, a ser tratada con dignidad o a tener garantizados derechos como la salud. El pleno derecho, en este decreto, se reduce a ser expulsada sin demoras ni incertidumbres. En este fragmento observamos otras formas de legitimación que justifican la necesidad del decreto:

- "es evidente": constituye una forma de evidencialidad directa (se puede ver). Tiene dos implicancias: por un lado, implica que es una obviedad, algo del sentido común; por otro lado, se asocia con la modalidad epistémica de certeza.

- "debe hacerse": modalidad deóntica (obligación). Es decir, el Estado se encuentra obligado a tomar la medida que está tomando, no tiene otra posibilidad o alternativa.

- "puede acarrear"; "pueden insumir alrededor de CUATROCIENTOS (400) días 
hábiles": modalidad epistémica de posibilidad ${ }^{10}$.

- Los casos de modalidad epistémica no marcada, es decir, que indican el grado máximo de certeza, refieren a la necesidad de modificación de la ley en relación con los marcos que -según vimos en el apartado 4.2- prevalecen en todo el texto, los derechos de las migrantes y la seguridad pública: "Esta circunstancia suscita incertidumbre al migrante"; "dificulta a la DIRECCIÓN NACIONAL DE MIGRACIONES el cumplimiento de su misión de garantizar el cumplimiento de la ley, lo que en última instancia repercute en la seguridad pública”.

\section{c) Conocimiento general}

Este recurso no requiere evidencia directa, pruebas ni razonamientos para su aceptación por parte de las lectoras porque se considera que lo que se predica sobre las migrantes es ya sabido por todas. De hecho, no solo no hay pruebas ni evidencias, sino que tampoco hay ninguna referencia concreta a qué "hecho de criminalidad organizada" alude:

8) "Que ante recientes hechos de criminalidad organizada de público y notorio conocimiento, el Estado Nacional ha enfrentado severas dificultades para concretar órdenes de expulsión dictadas contra personas de nacionalidad extranjera..."

Sin embargo, lo que se presenta como ya conocido y constatado por el público es un hecho de criminalidad organizada, no se afirma que ese hecho en particular tenga algo que ver con las migrantes. Esto debe inferirlo la lectora, en primer lugar, porque la referencia al crimen organizado se encuentra dentro de un decreto sobre migraciones y, en segundo lugar, porque en el mismo discurso ya se asoció a las extranjeras no solo con la delincuencia sino particularmente con el narcotráfico. Además, a nivel gramatical, el conector "ante" obliga a la lectora a aceptar (para que la conexión entre ambas cláusulas tenga sentido) que las "personas de nacionalidad extranjera" son las mismas que participaron de los "hechos de criminalidad organizada”. De otra manera, la conexión lógica entre ambas cláusulas carecería de sentido.

${ }^{10}$ Richardson (2007) señala que un menor grado de compromiso también puede tener efectos en la configuración de nuestra comprensión de un posible evento. La ambigüedad de las afirmaciones modales "más débiles", como es el caso de "puede", surge de la implicatura convencional asociada, que facilita la transmisión de proposiciones similares a sus contrapartes categóricas sin que la autora del texto tenga que comprometerse plenamente con su verdad. Todavía es posible que ocurra una coerción sobre la lectora en este contexto porque los modales más débiles pueden, paradójicamente, aumentar la sensación de temor o amenaza. 
d) Evidencialidad directa

En el fragmento 7 habíamos observado la utilización de "es evidente" que presenta la información como algo que se capta a través de la vista y que implica una modalidad epistémica de certeza. El efecto que produce es el de una verdad obvia e indiscutible. En el texto hay otros usos de evidencialidad directa que tampoco permitirían discusión en tanto un hecho es presentado como observado y comprobado por las mismas autoridades migratorias:

9) “...se ha detectado en el último año una nueva modalidad de fraude a la ley migratoria"

10) “...se ha advertido otra modalidad de fraude a la Ley Migratoria que hace indispensable modificar la Ley No 346 de Ciudadanía”

\subsubsection{Modalidad deóntica}

Si bien Hart (2010) no coloca a la modalidad deóntica como una forma de legitimación, la incluimos porque consideramos que genera el mismo efecto de inevitabilidad que generan algunos de los recursos evidenciales presentados en la sección anterior. La utilización de modalidad deóntica muestra como necesaria la sanción del decreto. En este sentido, a pesar de haber postulado la discrecionalidad que posee el Estado en materia migratoria, el discurso lo construye como un actor que se ve obligado a proceder debido a una situación ya previamente presentada como una verdad evidente:

11) "Que, también como consecuencia de los controles precedentemente mencionados, se ha advertido otra modalidad de fraude a la Ley Migratoria que hace indispensable modificar la Ley

12) “deviene imprescindible ajustar la legislación migratoria a la nueva realidad"

13) “...la naturaleza excepcional de la situación planteada hace imposible seguir los trámites ordinarios previstos en la Constitución Nacional para la sanción de las leyes."

14) Que, además, resulta imprescindible establecer pautas claras y objetivas sobre el procedimiento de retención.

15) Que el Estado debe regular la política migratoria teniendo en especial consideración el bien común.

16) Que el Estado Nacional debe velar por el orden internacional y la justicia, de conformidad con lo establecido en el artículo $3^{\circ}$, inciso j), de la Ley de Migraciones.

La reiteración de la nominalización "necesidad" también contribuye con la 
construcción del endurecimiento de las políticas migratorias como algo indispensable:

17) "Que la necesidad de trabajar incesantemente en el perfeccionamiento del orden normativo migratorio adquiere especial importancia frente a fenómenos actuales como la globalización, la internacionalización del turismo y el crecimiento del crimen organizado internacional.”

18) “...la necesidad de llevar adelante nuevas estrategias contra el delito y la violencia."

\section{CONSIDERACIONES FINALES}

En este trabajo, analizamos la construcción de las migrantes en los considerandos del decreto 70/2017 para observar qué representaciones construye el gobierno de Mauricio Macri (2015-2018) con respecto a las personas que provienen de diferentes países y de qué manera justifica la necesidad de un decreto que endurece la política migratoria. Partimos de la premisa de que las representaciones que el gobierno construye acerca de las migrantes repercuten en otras actitudes y decisiones que toma dicho gobierno y en los comportamientos tanto de funcionarias públicas como de ciudadanas que lo lean.

Para el análisis de las representaciones utilizamos dos propuestas metodológicas complementarias: la distribución de los procesos en los que aparece la participante correspondiente a las migrantes, ya sea en el rol de actora como en el de afectada por otra participante -el Estado Nacional-, y el estudio de los marcos conceptuales que se activan para hablar de las personas que provienen de otros países.

Los resultados de ambos análisis fueron consistentes. Las migrantes son asociadas con tres marcos conceptuales: los derechos, la delincuencia y la seguridad nacional. Los procesos que tienen a las migrantes como participante se vinculan de manera exclusiva con estos marcos. En su rol de actoras, se describen tanto las acciones que pueden realizar porque forman parte de sus derechos como los delitos que cometen. En el rol de afectadas, aparecen las medidas que corresponden al Estado tanto para garantizar los derechos de las migrantes como la seguridad de las argentinas.

Las personas que provienen de otros países son representadas como peligrosas, como una amenaza, que se ve reforzada por recursos de proximidad. Así, se busca despertar las respuestas instintivas que las personas humanas desarrollamos para responder a situaciones de peligro, en particular, físico: el miedo. Sin embargo, el propio decreto brinda la solución -evitar la situación de riesgo- endureciendo la política migratoria.

Por su parte, el análisis de los recursos de legitimación nos permitió observar cómo esas representaciones sobre las migrantes son construidas como una verdad 
objetiva, basada en evidencias y conocida por todas las ciudadanas, que, por lo tanto, vuelve necesarias las nuevas medidas decretadas. Para ello, en los considerandos del decreto, se repiten las formas directas de evidencia que implican una modalidad epistémica de certeza y, sobre todo, las expresiones propias de la modalidad deóntica que determinan la obligación del Estado de actuar. Además, el texto recurre a la utilización de estadísticas y porcentajes, citas de autoridad y razonamientos. En resumen, el decreto utiliza todos los tipos de evidencias posibles según la clasificación presentada en la Figura 1, de manera tal de no dejar ningún intersticio para cuestionar la verdad de su planteo y la inevitabilidad de la modificación a la legislación migratoria.

\section{REFERENCIAS}

Arias Duval, Martín. (2011). Prólogo. En DNM (Comp.). Nosotros, los que vinieron. Buenos Aires, Argentina: DNM, 10-11.

Amossy, Ruth y Herschberg Pierrot, Anne. (2010). Estereotipos y clichés. Buenos Aires, Argentina: Eudeba.

Bednarek, Monika. (2006). Epistemological positioning and evidentiality in English news discourse: A text-driven approach. Text \& Talk, 26(6), 635-660.

Chalmers, Alan. (1982). ¿Qué es esa cosa llamada ciencia? Buenos Aires, Argentina: Siglo XXI.

Fowler, Robert. (1991). Language in the news: Discourse and ideology in the press. London, United Kingdom: Routledge.

Fowler, Robert; Kress, Gunther; Hodge, Robert y Trew, Tony. (1983). Lenguaje y control. México DF, México: Fondo de cultura económica.

Giustiniani, Rubén. (2004). Migración, un derecho humano: ley de migraciones $N^{o}$ 25.871. Buenos Aires, Argentina: Prometeo.

Halliday, Michael y Matthiessen, Christian. (2014). Halliday's Introduction to Functional Grammar. London, United Kingdom y New York, United States: Routledge.

Hart, Christopher. (2010). Critical Discourse Analysis and Cognitive Science New Perspectives on Immigration Discourse. London, United Kingdom: Palgrave, Macmillan.

Hart, Christopher. (2014). Discourse, Grammar and Ideology. London, United Kingdom: Bloomsbury.

Hodge, Robert y Kress, Gunther. (1993). Language as Ideology (Second Edition). London, United Kingdom: Routledge \& Kegan Paul Books.

Kuhn, Thomas. (1990). La estructura de las revoluciones científicas. Buenos Aires, Argentina: Fondo de Cultura Económica. 
Lakoff, George. (2002). Moral Politics. How Liberals and Conservatives Think. Chicago, United States and London, United Kingdom: The University of Chicago Press.

Lakoff, George. (2010). Why it Matters How We Frame the Environment. Environmental Communication, 4(1), 70-81.

Oteiza, Enrique y Novick, Susana. (2010). Política migratoria y derechos humanos en un contexto de ajustes y reformas neoliberales. Argentina: 1989-1999 (gobierno de Menem). Disponible en http://pobmigraiigg.sociales.uba.ar/publicaciones/publicaciones/ [consulta 1/07/2018].

Richardson, John. (2007). Analysing newspapers: An approach from critical discourse analysis. Basingstoke, United Kingdom: Palgrave Macmillan.

Wittgenstein, Ludwig. (1978). Observaciones a los fundamentos de la matemática. Madrid, España: Alianza.

Wodak, Ruth. (2001). The discourse-historical approach. En Meyer, Michael y Wodak, Ruth (Comp.). Methods of critical discourse analysis. London: Sage, 63-94. 